\title{
NÁLEZ HLINÍKEM BOHATÝCH SPINELIDŮ A KORUNDU VE STRUSKÁCH PO TAVBĚ STŘíiRRYÝCH RUD ZE STŘí́BRNÝCH HOR NA HAVLÍČKOBRODSKU
}

\author{
Finding of the aluminum-rich spinelides and corundum in the slags produced by silver \\ metallurgy from the Stríbrné Hory in the Havlíčkưv Brod Ore District
}

Kateřina Janíčková, Zdeněk Dolníček

Katedra geologie, PřF UP Olomouc, tř. 17. listopadu 12, 77146 Olomouc; e-mail: janickova.katerina@email.cz

(23-22 Žd’ár n. Sázavou)

Key words: Havlíčkưv Brod Ore District, spinelides, corundum, slag, silver smelting

\begin{abstract}
This work deals with the unique association formed by spinelides and corundum in historical slag after smelting of silver ore from the site Stř́brné Hory in the Havlíčkův Brod Ore District. To study these phases, polarizing microscope and electron microprobe (WDX and EDX) were used. The slag consists primarily of glass and residual quartz, which also contained sillimanite needles. During smelting the quartz and sillimanite have been partially melted and aluminium-rich spinelides crystallized in the surrounding glass. Euhedral crystals of spinelides range 5 to $25 \mu \mathrm{m}$ in size and are composed predominantly of hercynite (55-58 mol. \%), to a lesser extent gahnite (21-24 mol. \%), spinel (18-24 mol. \%) and galaxite (4-5 mol. \%). Corundum probably originated during the smelting from secondary mullite at temperatures around $1300^{\circ} \mathrm{C}$. Corundum together with glass form a paramorphosis after sillimanite aggregate.
\end{abstract}

Úvod

Silikátové strusky vznikaly při tavení stř́brné rudy $\mathrm{v}$ peci roztavením nečistot $\mathrm{z}$ rudy, popelovin $\mathrm{z}$ použitého paliva a eventuálně i přidaných struskotvorných př́sad. Díky nižší hustotě struska plavala nad vyredukovaným kovem. Kromě novotvořených fází (krystalizujících z taveniny) mohou strusky obsahovat i neroztavené relikty vsázky spolu s dřevěným uhlím. Detailní studium strusek nám umožňuje poznat jejich fázové a chemické složení a následně rekonstruovat technologii hutnění a provenienci použitých surovin. Tyto artefakty mohou také pomoci datovat hutnické aktivity na lokalitě a podle objemu struskových hald přibližně určit rozsah těžby a hutnické výroby (Nováček 2001).

$\mathrm{V}$ předložené práci přinášíme popis neobvyklé minerální asociace ve strusce ze Stř́ibrných Hor, vzniklé na úkor sillimanitu. Nález je zajímavý vzhledem ke skutečnosti, že ve struskách sillimanit nebývá běžnou součástí.

Rozkvět těžby polymetalických rud $\mathrm{v}$ havlíčkobrodském revíru je datován do 2. pol. 13. stol. V okolí Stríbrných Hor bylo centrem hornických aktivit sídliště Herliwinberg. $\mathrm{V}$ pozdější době, přibližně od konce 13. století do 2. pol. 14. stol., dochází k úpadku těžby a zániku hornických sídlišṫ (Rous 2003). Kromě vytěžení nejbohatších a snadno dostupných partií zrudnění byl další příčinou útlumu hornictví v dané oblasti také nález kvalitní stř́brné rudy na Kutnohorsku (Stránský et al. 2001; Rous 2003). Těžba v okolí Strúbrných Hor nabyla nového rozmachu v 16. a 17. století. $\mathrm{V}$ této době docházelo $\mathrm{v}$ „horách přibyslavských“ $\mathrm{k}$ obnovování starých důlních děl i $\mathrm{k}$ ražbě děl nových. Díky rozvoji hornictví došlo $\mathrm{k}$ růstu vesnice Šicendorf a hornického sídliště Silberberg, které dnes spolu tvoří obec
Střibrné Hory (Rous 2003). O provozu zpracovatelských areálů v okolí Borovského potoka svědčí také nálezy několika torz mlecích kamenů z rudních mlýnů (Rous et al. 2005).

\section{Materiál a metodika}

Při odběru vzorků strusek pro diplomovou práci autorky (Janíčková 2013) byl v roce 2010 na lokalitě Stř́ibrné Hory 1 (vzdálené přibližně $800 \mathrm{~m}$ od centra obce Stř́ibrné Hory směrem na Přibyslav) nalezen také vzorek strusky s hliníkem bohatými spinelidy a korundem. Lokalita se nachází $\mathrm{v}$ zářezu levého břehu Borovského potoka, asi 20 metrů od mostu po směru toku (obr. 1). Z odebraného vzorku (označen 1.4) byly vyhotoveny leštěné výbrusy, které byly následně studovány $\mathrm{v}$ polarizačním mikroskopu v odraženém a procházejícím světle. Vzorek strusky 1.4 byl sklovitý s velkým podílem křemenných zrn. Sklo při zbroušení výbrusu na standardní tlouštku nebylo průhledné, $v$ místech ztenčení mělo žlutohnědou barvu a byla pozorována sférolitická struktura po rekrystalizaci skelné fáze. Zrna křemene byla př́tomna $\mathrm{v}$ celé ploše výbrusu, nejvíce při okrajích vzorku, obvykle byla zakalená, popraskaná a s undulózním zhášením. Struska obsahovala velké množství drobných nepravidelných až okrouhlých pórů. Ve výbruse byla také zachycena kompozičně nehomogenní okrouhlá sulfidická kapka složená z pyrhotinu a rudashevskyitu a s kostrovitým krystalem olivínu (Janíčková et al. 2012).

Nalezené spinelidy byly analyzovány v Ústavu geologických věd PřF MU v Brně elektronovou mikrosondou Cameca SX 100 ve WDX módu, korund byl vzhledem $k$ nepatrné velikosti zrn pouze ověřen pomocí EDX. Analýzy provedl dr. Petr Gadas. Pro analýzy spinelidů bylo 


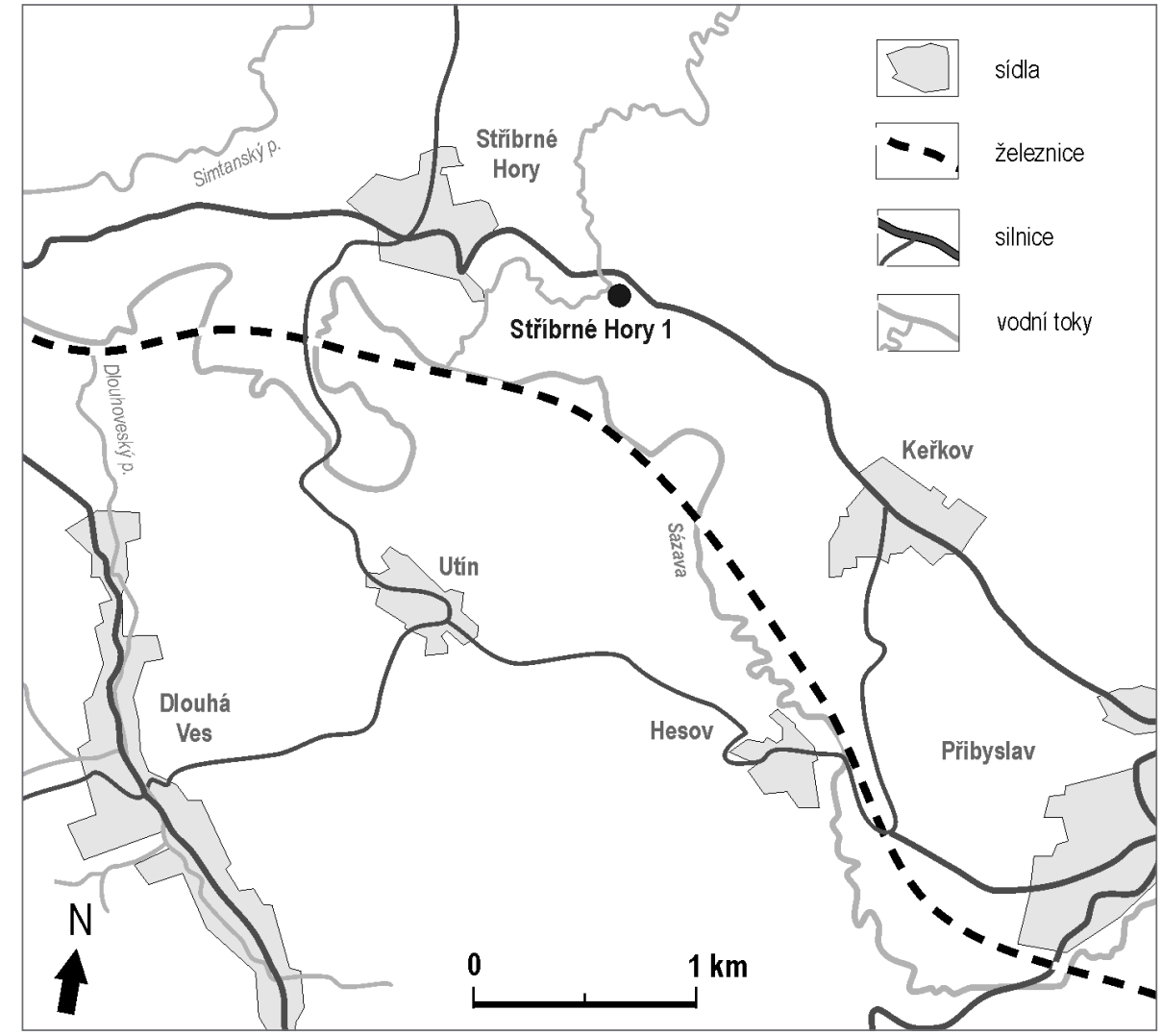

Obr. 1: Geografická pozice studované lokality. Bod Stř́brné Hory 1 označuje odběrové místo strusky 1.4 (upraveno podle www.mapy.cz).

Fig. 1: Geographic position of the studied site. Point Stříbrné Hory 1 represents location of site, where slag 1.4 was found (modified from www.mapy.cz).

použito napětí $15 \mathrm{kV}$, proud $20 \mathrm{nA}$, průměr elektronového svazku $2 \mu \mathrm{m}$ a následující standardy: $\mathrm{MgAl}_{2} \mathrm{O}_{4}(\mathrm{Mg}, \mathrm{Al})$, spessartin ( $\mathrm{Si}, \mathrm{Mn})$, titanit (Ti), chromit $(\mathrm{Cr})$, wollastonit (Ca), hematit (Fe), $\mathrm{ScVO}_{4}(\mathrm{~V}), \mathrm{Ni}_{2} \mathrm{SiO}_{4}(\mathrm{Ni})$, gahnit (Zn). Pro analýzu skla bylo použito napětí $15 \mathrm{kV}$, proudu $10 \mathrm{nA}$, průměr elektronového svazku $5 \mu \mathrm{m}$ a následující standar-
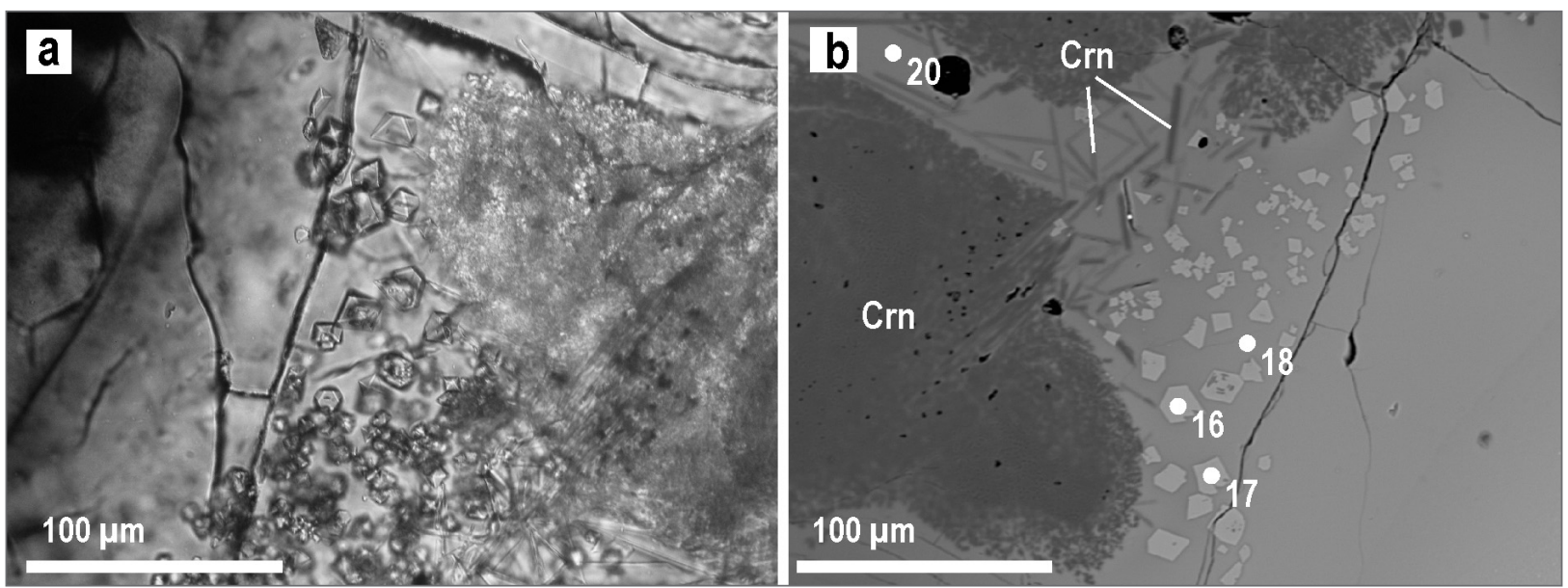

Obr. 2: Texturní rysy studované hliníkem bohaté minerální asociace vzorku 1.4. a - automorfní krystaly spinelidů ve skle v sousedství špatně průhledných agregátů tvořených korundem a sklem (výbrus, procházející světlo, PPL); b - světle šedé spinelidy ve skle (tmavší šedá) lemují agregáty složené z korundu a skla (Crn) (BSE, foto P. Gadas). Čísla v obrázku odpovídají číslům analýz v tabulce 1.

Fig. 2: Textural features of studied aluminium-rich mineral assemblage in the sample 1.4. a - euhedral crystals of spinelides in the glass adjacent to the poorly transparent aggregates formed by corundum and glass (thin section, transmitted light, PPL); b - light gray spinelides in glass (darker gray) lining an aggregate composed of corundum and glass (Crn) (BSE, photo by P. Gadas). Numbers in the figure correspond to the numbers of the analyses in table 1. dy: albit $\mathrm{A}(\mathrm{Na})$, almandin $(\mathrm{Fe})$, baryt $(\mathrm{Ba})$, gahnit $(\mathrm{Zn})$, chromit $(\mathrm{Cr}), \mathrm{Ni}_{2} \mathrm{SiO}_{4}(\mathrm{Ni})$, pyrop $(\mathrm{Mg}), \mathrm{ScVO}_{4}(\mathrm{~V})$, sanidin $(\mathrm{K})$, spessartin ( $\mathrm{Si}, \mathrm{Al}$, $\mathrm{Mn}), \mathrm{SrSO}_{4}(\mathrm{Sr})$, titanit (Ti), topaz $(\mathrm{F})$, vanadinit $(\mathrm{Cl})$, wollastonit $(\mathrm{Ca})$.

\section{Výsledky}

Sillimanit byl nalezen $\mathrm{v}$ jediném vzorku strusky v několika zrnech křemene. Tvořil zprohýbané vějírovité a vláknité agregáty či jednotlivé kratší rovné jehlice. Hliníkem bohaté spinelidy korundem byly nalezeny $s$ křemenem při kontaktu se veny. Při větším nahloučení byl agregát sillimanibyly bezbarvé a bez zakalení, interferenční barvy se pohybovaly mezi bílou až oranžovou I. řádu. Křemen byl popraskaný a místy slabě zakalený. Hliníkem bohaté spinelidy s korundem se nacházely v bezbarvém skle v blízkosti nataveného sillimanitu či jsou v bezprostředním kontaktu se sillimanitem. Spinelidy tvořily mnohdy hustě nahloučené polohy různě velkých v průhledu bezbarvých až lehce nazelenalých automorfně omezených oktaedrů o velikosti nejčastěji struskovou sklovinou nata- 
Tab. 1: Výsledky WDX analýz spinelidů a skla (hm. \%) ve vzorku 1.4. Empirický vzorec spinelidů je přepočítán na čtyři atomy kyslíku. V př́padě, že to bylo možné, je dvojmocné a trojmocné železo rozpočteno na sumu 3 kationtů. Obsahy koncových členů jsou uvedeny v mol. \%.

Tab. 1: Results of WDX analyses of spinelides and glass (wt.\%) in the sample 4.1. Empirical formulae of spinelides are based on four oxygen atoms. If possible, the divalent and trivalent iron is recalculated on the sum of three cations per formula unit. The contents of endmembers are given in mol. \%.

\begin{tabular}{|c|c|c|c|c|c|c|}
\hline \multicolumn{4}{|c|}{ Spinelidy } & \multicolumn{3}{|c|}{ Sklo } \\
\hline Číslo analýzy & 16 & 17 & 19 & Číslo analýzy & 18 & 20 \\
\hline $\mathrm{SiO}_{2}$ & 0,33 & 0,05 & 0,04 & $\mathrm{SiO}_{2}$ & 49,68 & 54,42 \\
\hline $\mathrm{TiO}_{2}$ & 0,07 & 0,05 & 0,01 & $\mathrm{TiO}_{2}$ & 0,64 & 1,84 \\
\hline $\mathrm{Al}_{2} \mathrm{O}_{3}$ & 58,80 & 59,43 & 58,77 & $\mathrm{Al}_{2} \mathrm{O}_{3}$ & 20,42 & 21,37 \\
\hline $\mathrm{V}_{2} \mathrm{O}_{3}$ & 0,08 & 0,08 & 0,07 & $\mathrm{~V}_{2} \mathrm{O}_{3}$ & 0,01 & 0,04 \\
\hline $\mathrm{Cr}_{2} \mathrm{O}_{3}$ & 0,23 & 0,33 & 0,16 & $\mathrm{Cr}_{2} \mathrm{O}_{3}$ & 0,02 & 0,01 \\
\hline $\mathrm{Fe}_{2} \mathrm{O}_{3}$ & 0 & 0 & 1,20 & $\mathrm{MgO}$ & 1,28 & 3,08 \\
\hline $\mathrm{MgO}$ & 5,43 & 5,65 & 4,09 & $\mathrm{CaO}$ & 4,35 & 1,12 \\
\hline $\mathrm{CaO}$ & 0,08 & 0,04 & 0,05 & $\mathrm{MnO}$ & 2,39 & 0,36 \\
\hline $\mathrm{MnO}$ & 1,76 & 1,61 & 2,07 & $\mathrm{FeO}$ & 13,71 & 8,60 \\
\hline $\mathrm{FeO}$ & 23,27 & 23,13 & 23,24 & $\mid \mathrm{ZnO}$ & 0,92 & 0,17 \\
\hline $\mathrm{NiO}$ & 0,04 & 0,05 & 0,01 & $\mathrm{BaO}$ & 0 & 0,09 \\
\hline $\mathrm{ZnO}$ & 9,66 & 10,26 & 11,02 & $\mathrm{Na}_{2} \mathrm{O}$ & 1,15 & 1,60 \\
\hline Suma & 99,77 & 100,68 & 100,73 & $\mathrm{~K}_{2} \mathrm{O}$ & 3,76 & 5,36 \\
\hline $\mathrm{Si}^{4+}$ & 0,009 & 0,001 & 0,001 & $\mathrm{~F}$ & 0,08 & 0,21 \\
\hline $\mathrm{Ti}^{4+}$ & 0,001 & 0,001 & 0 & $\mathrm{Cl}$ & 0,00 & 0,02 \\
\hline $\mathrm{Al}^{3+}$ & 1,960 & 1,966 & 1,964 & Suma & 98,41 & 98,34 \\
\hline $\mathrm{V}^{3+}$ & 0,002 & 0 & 0,001 & & & \\
\hline $\mathrm{Cr}^{3+}$ & 0,005 & 0,007 & 0,004 & & & \\
\hline $\mathrm{Fe}^{3+}$ & 0 & 0 & 0,026 & & & \\
\hline $\mathrm{Mg}^{2+}$ & 0,229 & 0,236 & 0,173 & & & \\
\hline $\mathrm{Ca}^{2+}$ & 0,002 & 0,001 & 0,002 & & & \\
\hline $\mathrm{Mn}^{2+}$ & 0,042 & 0,038 & 0,050 & & & \\
\hline $\mathrm{Fe}^{2+}$ & 0,551 & 0,543 & 0,551 & & & \\
\hline $\mathrm{Ni}^{2+}$ & 0,001 & 0,001 & 0 & & & \\
\hline $\mathrm{Zn}^{2+}$ & 0,202 & 0,213 & 0,231 & & & \\
\hline$\sum$ kat & 2,994 & 2,996 & 3,000 & & & \\
\hline$\sum \mathrm{M}^{3+}$ & 1,967 & 1,966 & 1,994 & & & \\
\hline$\sum \mathrm{M}^{2+}$ & 1,027 & 1,030 & 1,006 & & & \\
\hline \multicolumn{4}{|c|}{ mol. \% koncových členů } & & & \\
\hline Gahnit & 23,0 & 21,9 & 23,0 & & & \\
\hline Hercynit & 54,8 & 55,3 & 53,4 & & & \\
\hline Spinel & 17,2 & 17,7 & 17,3 & & & \\
\hline Galaxit & 5,0 & 5,1 & 5,0 & & & \\
\hline Magnetit & - & - & 1,3 & & & \\
\hline
\end{tabular}

od 5 do $25 \mu \mathrm{m}$. Zonálnost nebyla pozorována u žádného ze zrn ani ve světelném mikroskopu, ani v obraze BSE (obr. 2). Reprezentativní kvantitativní chemické analýzy jsou v tabulce 1. Převažující komponentou spinelidů byl hercynit (53-55 mol. \%), v menším množství se dále objevuje gahnitová (22-23 mol. \%), spinelová (17-18 mol. \%) a galaxitová komponenta (5 mol. \%), v analýze č. 19 byla potvrzena také magnetitová komponenta (1,3 mol. \%). Korund byl potvrzen mikrosondou a tvořil spolu se sklem pseudomorfózy po sillimanitu. Korund byl bezbarvý a tvořil jemnozrnné izometrické až lištovité agregáty. Úzké lišty byly nejčastěji dlouhé okolo $30 \mu \mathrm{m}$. Korund a spinelidy se nacházely jen v nejbližším okolí sillimanitu v průhledné sklovině vzniklé z nataveného křemene. V tmavší hnědé sklovině strusky (z partií neobsahujících uzavřeniny sillimanitu) už ̌ádné z těchto fází nalezeny nebyly. Průhledné sklo analyzované v okolí výše popsaných fází (tab. 1) má na rozdíl od skel popsaných z okolí jiných fází strusky zvýšené obsahy některých oxidů $\left(20,4-21,4 \mathrm{hm} . \% \mathrm{Al}_{2} \mathrm{O}_{3}\right.$, $8,6-13,7$ hm. \% FeO a 0,4-2,4 hm. \% MnO) a naopak nižší obsah $\mathrm{ZnO}(0,17-0,92 \mathrm{hm}$. \%). Pro srovnání se obsahy $\mathrm{Al}_{2} \mathrm{O}_{3}$ ve skle $\mathrm{z}$ jiných vzorků strusek $\mathrm{z}$ havlíčkobrodského revíru pohybovaly v rozmezí $2,5-13,4 \mathrm{hm}$. \%, FeO v rozmezí 1,3-7,6 hm. \%, MnO v rozmezí 0,20-5,27 a ZnO v rozmezí 0,37-6,11 hm. \% (Janíčková 2013). Chemické složení skla odpovídá fázím obklopeným sklem, proto jsou nejvíce zvýšené právě ty oxidy, které se podílejí na složení spinelidů a korundu (Janíčková 2013).

\section{Diskuze a závěr}

Tavba strusek probíhá při běžném tlaku v teplotním rozmezí 1100 až $1300^{\circ} \mathrm{C}$ (Mannase a Mellini 2002). Shaw a Arima (1998) však stanovili pro př́mou přeměnu sillimanitu na korund při teplotě $1100^{\circ} \mathrm{C}$ tlak 12 kbar. Takových podmínek ovšem nebylo možné v běžné středověké peci dosáhnout.

Jako daleko pravděpodobnější se proto jeví možnost vzniku korundu ze sekundárního mullitu, který při běžném tlaku může začít ze sillimanitu vznikat za teplot od přibližně $1300{ }^{\circ} \mathrm{C}$ (Bartouška et al. 2007). Při další interakci mullitu se sklem bohatým na hliník (až 21,4 hm. \% $\mathrm{Al}_{2} \mathrm{O}_{3}$ ) mohl vznikat čistý korund a spinelidy s neobvyklým složením. Jak uvádí Kušnierová et al. (2011), obdobně se chovaly elektrárenské popílky, které obsahovaly krysta-

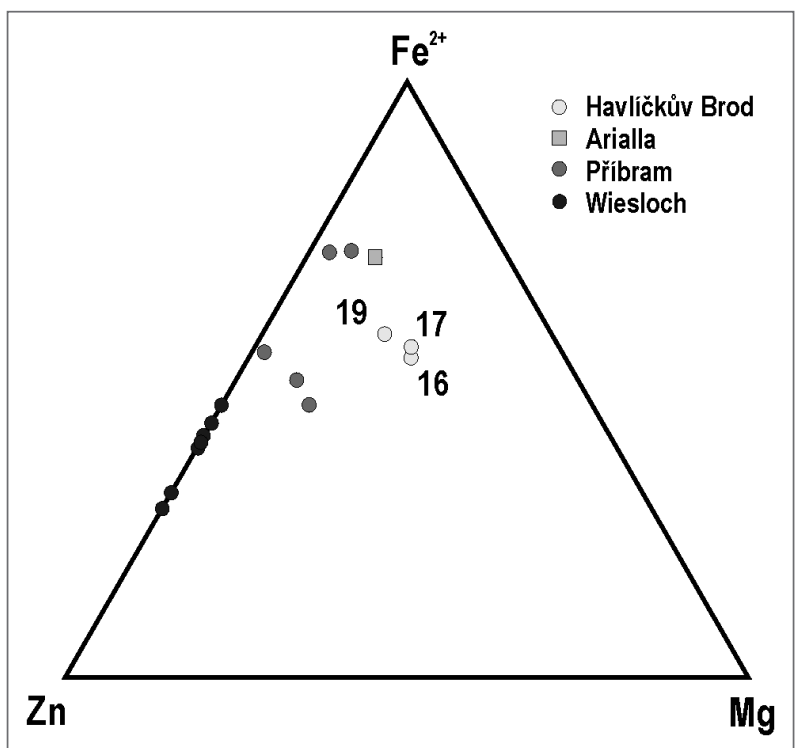

Obr. 3: Znázornění chemismu spinelidů řady gahnit-hercynit-spinel. Čísla v diagramu odpovídají číslům analýz v tab. 1. Srovnávací data jsou ze strusek z Arially (Manasse a Mellini 2002), Př́brami (Ettler et al. 2001, 2009) a Wieslochu (Ströbele et al. 2010).

Fig. 3: Visualization of the chemistry of spinelides of the gahnite-hercynite-spinel series. The numbers in the diagram correspond to the numbers of analyses in tab. 1. Comparative data are from slags from Arialla (Manasse and Mellini 2002), Př́bram (Ettler et al. 2001, 2009) and Wiesloch (Ströbele et al. 2010). 
lický mullit $(2,9 \mathrm{hm} . \%)$ a amorfní fázi složenou převážně z $\mathrm{Al}_{2} \mathrm{O}_{3}\left(23,7 \mathrm{hm}\right.$. \%) a $\mathrm{SiO}_{2}(64 \mathrm{hm}$. \%). Při zvyšování teploty od 850 do $1050^{\circ} \mathrm{C}$ docházelo ke snížení množství skelné fáze a přibývání sekundárního mullitu $(33,8 \mathrm{hm}$. \%) doprovázeného vznikem korundu $(1,4 \mathrm{hm}$. \%), spinelů $(2,1 \mathrm{hm} . \%)$ a křemene $(0,9 \mathrm{hm}$. \% křemene) (Kušnierová et al. 2011). Při ochlazení hliníkem velmi bohaté skloviny vznikly v konečné fázi spinelidy nezvyklého složení, které jsou ve stř̌edověkých struskách po tavbě barevných kovů unikátní (obr. 3).

\section{Poděkování}

Autoři děkuji dr. Petru Gadasovi (MU Brno) za asistenci při práci na elektronové mikrosondě. Práce byly finančně podpořeny projekty IGA UP PřF/2012/004 a IGA UP Př $F / 2013 / 010$.

\section{Literatura}

Bartouška, M. - Bauer, L. - Bubeník, J. - Exnar, P. - Hulínský, V. - Kloužek, J. - Maryška, M. - Matěj, J. - Němec, L. - Nováková, H. - Ohlídal, M. - Smrček, A. - Ullrich, J. (2007): Glass defects. - Práh. Praha.

Ettler, V. - Červinka, R. - Johan, Z. (2009): Mineralogy of medieval slags from lead and silver smelting (Bohutín, Př́íbram district, Czech republic): towards estimation of historical smelting condition. - Archaeometry 51, 6, 987-1007.

Ettler, V. - Legendre, O. - Bodénan, F. - Touray, J.-C. (2001): Primary phases and natural weathering of old lead-zinc pyrometallurgical slag from Př́bram, Czech Republic. - The Canadian Mineralogist, 39, 873-888.

Janíčková, K. - Dolníček, Z. - Malý, K. (2012): Fázové složení strusek po tavbě stříbrných rud na havlíčkobrodsku. - Geologické výzkumy na Moravě a ve Slezsku, XIX, 186-189. Brno.

Janíčková, K. (2013): Mineralogie a chemismus strusek po tavbě stř́brných rud z vybraných lokalit v havlíčkobrodském rudním revíru. - MS, diplomová práce. Univerzita Palackého v Olomouci.

Kušnierová, M. - Praščáková, M. - Matýsek, D. - Čablík, V. (2011): Mullitization of black coal fly ash. - Acta Montanistica Slovaca, 16, 3, 192-196.

Manasse, A. - Mellini, M. (2002): Chemical and textural characterisation of medieval slags from the Massa Marittima smelting sites (Tuscany, Italy). - Jurnal of Cultural Heritage, 3, 187-198.

Nováček, K. (2001): Nerostné suroviny středověkých Čech jako archeologický problém. - Archeologické rozhledy, 53, 279 -309.

Rous, P. (2003): Stř́ibrorudné hornictví na Havlíčkobrodsku od 13. do 17. století. - Archeolgia technica, 15, 49-58. Brno.

Rous, P. - Havlíček, J. - Malý, K. (2005): Nálezy mlecích kamenů z rudního mlýna na katastru Stř́ibrné Hory na Havlíčkobrodsku. - In: Stř́brná Jihlava 2004. Seminář k dějinám hornictví a důlních prací na Vysočině. 128-134. Jihlava.

Shaw, R. K. - Arima, M. (1998): A corundum-quartz assemblage from the Eastern Ghats Granulite Belt, India: evidence for high P-T metamorphism? - Jurnal of Metamorphic Geolology, 16, 189-169.

Stránský, K. - Brhel, J. - Blažíková, J. (2001): Stř́brné Hory u Přibyslavi - rozbor rud a strusek po zpracování stř́ibra. - Z dějin hutnictví, 30, 68-76. Praha.

Ströbele, F. - Wenzel, T. - Kronz, A. - Hildebrandt, L. H. - Markl, G. (2010): Mineralogical and geochemical characterization of high-medieval lead-silver smelting slags from Wiesloch near Heidelberg (Germany) - an approach to process. - Archaeological and Anthropological Sciences, 2, 191-215. 